\title{
Externalizing Disorders in Albanian Adolescents: Age and Gender Differences in a Large Sample of Secondary School Pupils
}

\author{
Marsel Cara, PhD (c) \\ University of "Sapienza", Rome, Italy
}

Doi: 10.2478/jesr-2018-0010

\begin{abstract}
Externalizing disorders (ED) refer to behaviours of a child/adolescent that negatively affect persons external to them. So far, no large-scale study on ED in adolescents attending secondary schools has been carried out in Albania. The current study explored gender and age differences in relation to externalizing disorders (ED) in a large sample of adolescents in 8 secondary schools situated in Tirana, the capital of Albania. The study adopted a mixed-methods approach. A survey consisting of two questionnaires SDQ-T and WOST were completed by 42 teachers (randomly selected) on 614 pupils randomly selected in their K7-9 classes. The teachers were divided in 4 groups which participated in one focus group meeting. Gender-related differences confirmed previous studies that indicate a higher prevalence of ED in the male population. Evidence on age-related differences was mixed, with quantitative data indicating higher levels of ED in the 14 and 15-year olds in comparison with the 13year olds, and qualitative data suggesting the opposite trend, that is, higher levels in 13-year olds attending year 7 adjusting to transition in secondary schools, gradually decreasing in years 8 \& 9 . Recommendations based on the findings of the study are given regarding interventions that should target coping with school transitions in secondary school, promoting positive social skills and competencies, emotion regulation techniques and awareness of risks related to unsupervised use of social apps/media in schools.
\end{abstract}

\section{Introduction}

Externalizing disorders (ED) refer to behaviours of a child/adolescent that negatively affect persons external to them. These problematic behaviours commonly include noncompliance, aggression, impulsive behaviours, arguing, rule breaking, and property destruction (Jenson, Harward and Bowen, 2011). Externalizing disorders are the main concern for teachers who struggle to teach while trying to manage disruptive and challenging behaviours directed at them and/or at other students. Educational policy in Albania doesn't allow school principals/boards to exclude from compulsory education classes (K1-9) pupils who display repeatedly "unacceptable" behaviours at school. They have to be dealt with within the school/classroom. Recent initiatives like the COMBI teacher training on discipline have been implemented, in order to serve as a prevention strategy for behaviour problems. Such interventions, however, have not been systematically assessed for their efficaciousness (MASH, 2012).

About half of all lifetime cases of mental disorders begin by age 14 . Approximately $50 \%$ of students age 14 and older living with serious mental illness drop out of high school, the highest rate of any disability group (US Department of Education, 2006). However, it is simply not useful for educators and parents to explain the apparently drastic change in the incidence of problematic behaviours by using "general" non-operational predictors, such as adolescence. Many adolescents, indeed most of them, do not exhibit externalizing disorders. As a matter of fact, there is no single cause of conduct disorders (Rutter, 2003). 


\section{Literature Review}

Lahey and Waldman $(2003,2005)$ proposed a theoretical model that integrates current findings on the development of conduct problems, according to which children are born with individual differences in dispositions (e.g. temperament) to respond socially and emotionally to the environment. Variation in these dispositions among children are influenced by genes and prenatal influences and are shaped by the postnatal environment from birth onward (family, school, peers, media, etc.). The model was advanced to integrate the vast accumulation of empirical findings on the aetiology and origins of youth antisocial behaviour, as well as, to stimulate empirical research that might refute its hypotheses. Students who display problematic behaviours, often share certain negative temperamental predispositions (Gilliom \& Shaw, 2004; Waldman et al, 2011) experience family stressors such as parental divorce, rejection, coercive interactions, lack of discipline or supervision (Snyder \& Stoolmiller, 2002), and are influenced by negative peer cultures (Dishion, McCord \& Poulin, 1999). In respect to gender, males seem to outnumber females in conduct problems and delinquent activity by at least 3:1 (Leahy et al, 2006). Children and adolescents from the lower socioeconomic strata (SES), particularly males from larger urban areas, exhibit more aggressive behaviour and higher levels of delinquency than their age-mates from the middle class (Macmillan, McMorris, \& Kruttschnitt, 2004; Tolan, Gorman-Smith, \& Henry, 2003). These trends appear to be closely linked to social-class differences in child rearing. In respect to age, Albanian teachers and school psychologists indicate the transitional years of K5-9 as the most troublesome years, a period of schooling that coincides with early adolescence (12-15 years). These reports appear to support Moffit"s $(1993,2003)$ theoretical distinction between childhood-onset (caused mainly by biological, family and early social experiences) and adolescent-onset (caused by peer influences) trajectories of conduct problems in youths.

The role of the peer group in adolescence-limited offending is extremely important. One of the strongest predictors of delinquency and other forms of problem behaviour is the amount of time the adolescent spends in unsupervised, unstructured activities with peers-activities like hanging out, driving around, and going to parties (Steinberg, 459). Poor parenting usually leads to hanging out with deviant peers. Further accumulation of risk may occur via exposure to violence in high-risk neighbourhoods, early escalation of substance use, low motivation, and learning difficulties. By middle childhood and adolescence, exposure to stimulant drugs of abuse compromises the development of executive functions and self-regulation, compounding problem behaviours (Neuhaus \& Beauchaine, 2013).

According to the coercive model (Patterson, 1982), antisocial behaviour often functions to reduce an aversive interpersonal experience. During childhood to adolescence, caregivers giving negative feedback reinforces the problem behaviour. Coercive interactions between the parent and child consist of a cycle of intrusive demands, compliance refusals, escalating distress and negative affect, and finally, withdrawal of the demand. A high rate of coercive behaviour between the parent and child sets the stage for more serious antisocial behaviour. Furthermore, the impact of contextual variables, such as divorce, poverty, and neighbourhood risk, on child outcomes is proposed to be mediated by their impact on parenting practices (Beauchaine \& Hinshaw, 2013).

\section{Research Design}

The current study adopts a mixed-methods approach and is cross-sectional and correlational; it explores the relation of a dependent variable (externalizing disorders) with two multi-level independent variables (gender and age) in a large sample of Albanian adolescents randomly recruited in 8 large secondary schools in Tirana, Albania. So far, no such systematic large-scale empirical study focusing on ED has been carried out in Albania. Identifying, measuring and further understanding the variables (and co-variables) that have a significant effect on externalizing disorders in Albanian children going through early adolescence, might be extremely useful for identifying those more at risk, as well as, informing more specific prevention/intervention strategies which can be assessed/measured for efficaciousness using empirically generated specific indicators/outcomes. 
The following hypotheses were tested:

$\mathrm{H}_{1}$ : Gender will have a significant relationship with adolescent externalizing disorders (ED)

$\mathrm{H}_{0}$ : No gender differences will be found in relation to adolescent ED

$\mathrm{H}_{2}$ : Age will have a significant relationship with adolescent ED

$\mathrm{H}_{0}$ : No age differences will be found in relation to adolescent ED

\section{Research Methods}

\subsection{Sampling and Participants}

Six school psychologists working in 8 secondary schools in Tirana ( 7 public, 1 private) were invited to participate in the study as key informants on the schools' characteristics and as liaisons with the school personnel (principals, teachers) and parents/students (obtaining written consent). The schools were randomly selected from a list of public and private schools in the territory of Tirana. 43 teachers were randomly selected and invited to participate in the study. 42 teachers responded positively and completed surveys on 614 students randomly selected in 42 classrooms in the years $\mathrm{K} 7-9$, aged 12-16. Teachers were also invited to participate in 4 focus groups (10-11 persons each).

\subsection{Instruments and Procedures}

Teachers completed a survey that included two questionnaires: Strengths and Difficulties Questionnaire (SDQ-T, teacher version) and Wider Outcomes Survey for Teachers (WOSTAlbanian). Both questionnaires are freely available and are found to be useful in large-scale school surveys focusing on problematic behaviours, bullying, and pro-social behaviours. Surveys were anonymous, and codes known exclusively to the researcher were used to identify the participants. The data were processed in IBM SPSS 23. Teachers were randomly divided in 4 groups and participated in focus groups where discussions were organized around the following themes: ED relationship with gender, age, school and community characteristics, parenting styles and SES/family structure. However, only quantitative and qualitative data and relevant discussion on the effects of gender and age have been included in the current paper.

\section{Results and Discussion}

\subsection{Gender differences}

One-way between subjects ANOVA showed that teachers reported (WOST) significantly higher levels of problematic behaviours $[F(1,600)=126.22, p<.001)$ for males $(n=315 ; M=1.81 ; S D=.87)$ than for females $(n=287 ; M=1.18 ; S D=.36)$, and significantly higher levels of bullying/victimization [F $(1,600)=43.55, p<.001)$ among males $(M=1.5 ; S D=.52)$ than females $(M=1.24 ; S D=.38)$. Female students seemed to display a higher level of positive relationships $(M=3.35 ; S D=.53)$ than males $(\mathrm{M}=2.97 ; \mathrm{SD}=.65),[\mathrm{F}(1,599)=60.251, \mathrm{p}<.001]$.

SDQ-T scores similarly revealed higher levels of conduct problems, hyperactivity, and problem with peers for males, as well as higher levels of pro-social behaviours for females. A significant difference was also found in relation to emotional problems $\left[F(1,600)={ }^{\prime} 19.55, p<.001\right]$, with males $(M=1.94 ; S D=2.33)$ displaying more emotional problems than females $(M=1.19$; $S D=1.72$ ). This finding would suggest that the relationship between internalizing and externalizing disorders in males is worth investigating in early adolescence.

Teachers in the focus groups meeting corroborated the findings that male students display significantly higher levels of externalizing disorders (problematic behaviour in the classroom, hyperactivity, oppositional verbal and physical behaviour, truancy, overt aggressive behaviour towards peers, and bullying/victimization). However, female students were sometimes found to be indirectly inciters of conflict and violence between males of the same school or even between males 
of two different schools. In the latter case, Facebook was used (an activity that escapes the supervision of adults) to provoke "rivals"and arrange meetings for group fights in order to settle scores. It seems that programmes tailored especially for adolescents using social apps/media which provide information on the risks that misuse or abuse of these tools may pose, could be useful in secondary schools. Teachers reported that relying on them to implement "no smartphone on the premises" policies was not only unfair, considering their overwhelming teaching and administrative duties, but could also be unproductive, often resulting in conflict and disruption of regular activities in the classroom.

Cultural norms which widely "tolerate" a direct involvement of males in externalizing disorders as part of "growing up", or "becoming a man", and a more indirect role for females (considered a "typically" feminine trait), was the most often cited explanation for the gender-related differences, followed by earlier maturity achievement for girls and better overall observed ability to control impulsivity and regulate negative emotional states such as frustration, anger and boredom in the classroom.

\subsection{Age differences}

One-way between subjects ANOVA conducted on WOST scores showed a significant effect of age on problematic behaviours $[F(4,600)=2.89, p=.022]$ and bullying $[F(4,600)=3.46, p=.008]$. GamesHowell post-hoc tests showed higher levels of problematic behaviours among the 15-year olds $(n=163 ; M=1.58 ; S D=.78)$ and 14-year olds $(n=217 ; M=1.56 ; S D=.79)$ in comparison to the 13-year olds ( $n=178 ; M=1.36 ; S D=.61)$. A significant difference between two age groups was found in relation to bullying/victimization with 15-year olds displaying higher levels of victimization in the classroom $(M=1.44 ; S D=.51)$ than 13-year olds $(M=1.27$; $S D=.43)$. No significant difference was found in relation to prosocial behaviours.

One-way between subjects ANOVA conducted on SDQ-T scores revealed no significant differences in relation to conduct problems, emotional problems, hyperactivity, problems with peers and prosocial behaviours.

However, in the focus groups teachers from 4 different schools contradicted these findings with their observations of problematic behaviours and bullying being at their highest levels in the 13-year olds, gradually decreasing in the 14-year olds, only to be displayed at a moderate-low level in the 15-year olds. This change, according to the teachers, could be explained by the fact that tension is higher and relationships and social roles not clearly defined among 13-year old males who are getting to know each-other, are starting form groups and establish a "hierarchy" in the classroom. Once these relationships and social hierarchy are clearly defined, aggressive behaviour and bullying levels tend to decrease. However, an alternative explanation, which would find support from the quantitative data above, could be that 15-year olds get better at hiding their bullying from teachers in comparison to 13-year olds - problematic behaviours do not actually decrease, they are simply perceived by some teachers as occurring less often and with lower intensity.

It seems that interventions targeting male adolescents offering programs dealing with coping with stressful school transitions via meditation and other empirically-based techniques of emotion regulation, initiating and maintaining positive social relationships, preventing bullying could be useful in secondary schools.

\section{Conclusion}

The study explored gender and age differences in relation to externalizing disorders (ED) in a large sample of adolescents in 8 secondary schools situated in Tirana, the capital of Albania. Genderrelated differences confirmed previous studies that indicate a higher prevalence of ED in the male population.

Evidence on age-related differences was mixed, with quantitative data indicating higher levels of ED in the 14 and 15-year olds in comparison with the 13-year olds, and qualitative data suggesting the opposite trend, that is, higher levels in 13-year olds attending year 7adjusting to 
transition in secondary schools, gradually decreasing in years $8 \& 9$. The study suggests that interventions with male adolescents in year 7 targeting the stressful tasks of school transition and competencies related to form positive relationships and social problem-solving could be necessary. However, in the context of Albanian schools, carefully designed programs in close collaboration with school psychologists and teachers should be empirically tested for effectiveness. No such studies so far have been conducted/published. Another recommendation would regard the use of social apps/media in schools, sometimes to incite conflict and violence, as well as the supervision of their use by adolescents. Although some of the schools participating in the study have a "no smartphone on the premises" policy, implementing it depends on the authority and ability of teachers who often see this task as an undesirable burden added to their teaching and administrative duties, which when carried out without flexibility can sometimes result in conflict and disruption of the regular classroom activities.

\section{References}

Beauchaine, T., Hinshaw, S. (eds.) (2013) Child and adolescent psychopathology. $2^{\text {nd }}$ ed. John Wiley \& Sons, Inc. New Jersey.

Dishion, T.J., McCord, J., \& Poulin, K. (199) When interventions harm: Peer groups and problem behaviour. American Psychologist, 54, 755-764.

Gilliom, M., \& Shaw, D. S. (2004). Co-development of externalizing and internalizing problems in early childhood. Development and Psychopathology, 16, 313-333.

Lahey, B. B., \& Waldman, I. D. (2003). A developmental propensity model of the origins of conduct problems during childhood and adolescence. In B. B. Lahey, T. E. Moffitt, \& A. Caspi (Eds.), Causes of conduct disorder and serious delinquency (pp. 76-117). New York, NY: Guilford Press. Lahey, B. B., \& Waldman, I. D. (2005). A developmental model of the propensity to offend during childhood and adolescence. In D. P. Farrington (Ed.), Advances in criminological theory (Vol. 13, pp. 15-50). Piscataway, NJ: Transaction.

Lahey, B. B., Van Hulle, C. A., Waldman, I. D., Rodgers, J. L., D"Onofrio, B. M.,Pedlow, S.,Keenan, K. (2006). Testing descriptive hypotheses regarding sex differences in the development of conduct problems and delinquency. Journal of Abnormal Child Psychology, 34, 737-755. Macmillan, R., McMorris, B. J., \& Kruttschnitt, C. (2004). Linked lives: Stability and change in maternal circumstances and trajectories of antisocial behavior in children. Child Development, 75, 205- 220.

MASH (2012) COMBI (communication for behaviour change): new techniques of discipline in the classroom. Ministry of Education and Science: Tirana, Albania

Moffitt, T.E. (1993). "Life-course persistent" and "adolescent-limited" anti-social behaviour: A developmental taxonomy. Psychological Review, 100, 674-701.

Moffitt, T.E. (2003) Life-course persistent and adolescent-limited antisocial behaviour: A 10-year research review and research agenda. In B.B. Lahey, T.E. Moffit, \& A.Caspi (Eds), Causes of conduct disorder and juvenile delinquency (pp.49-75), New York: Guilford Press.

Rutter, M. (2003). Crucial paths from indicator to causal mechanism. In B.H. Lahey, T.E. Moffitt, \& A. Caspi (Eds.), Causes for conduct disorder and juvenile delinquency (pp.3-26), New York: Guilford Press.

Snyder J., \& Stoolmiller, M. (2002) Reinforcement and coercive mechanisms in the development of antisocial behaviour: Peer relationships. In J.R. Reid, G.R. Patterson, \& J. Snyder (Eds.), Antisocial behavior in children and adolescents: A developmental analysis and model for intervention (pp.101-123). Washington, DC: American Psychological Association

Tolan, P. H., Gorman-Smith, D., \& Henry, D. B. (2003). The developmental ecology of urban males" youth violence. Developmental Psychology, 39, 274-291 U.S. Department of Education. (2006). Twenty-eighth annual report to Congress on the implementation of the Individuals with Disabilities Education Act, 2006 (Vol. 2). Washington, DC: U.S. Department of Education.

Waldman, I. D., Tackett, J. L., Van Hulle, C. A., Applegate, B., Pardini, D., Frick, P. J., \& Lahey, B. B. (2011). Child and adolescent conduct disorder substantially shares genetic influences with three socioemotional dispositions. Journal of Abnormal Psychology, 120, 57-70. 